Article

\title{
Structural, Vibrational and Electrochemical Analysis and Antibacterial Potential of Isomeric Chalcones Derived from Natural Acetophenone
}

\author{
Priscila Teixeira da Silva ${ }^{1}$ (D), Thiago Sampaio de Freitas ${ }^{1}$, Diniz Maciel Sena, Jr. ${ }^{1}{ }^{(}$, \\ Paulo Nogueira Bandeira ${ }^{2}$, Murilo Ségio da Silva Julião ${ }^{2}$, Emmanuel Silva Marinho ${ }^{3} \mathbb{E}^{-}$, \\ Ana Aline Coêlho Alcanfor ${ }^{4}$, Emanuelle Machado Marinho ${ }^{4}$, Pedro de Lima-Neto ${ }^{4}$ (D), \\ Carlos Emídio Sampaio Nogueira 1,5 , Henrique Douglas Melo Coutinho ${ }^{1}$, \\ Antonio Linkoln Alves Borges Leal ${ }^{1,6} \mathbb{( D}^{\mathbb{D}}$, Humberto Medeiros Barreto ${ }^{6}\left(\mathbb{D}\right.$, Natália Martins ${ }^{7,8, *(\mathbb{D})}$, \\ Alexandre Magno Rodrigues Teixeira ${ }^{1}$ (D) and Hélcio Silva dos Santos $1,2,9, *$ (D) \\ 1 Departamento de Química Biológica, Universidade Regional do Cariri, Crato CE 63.105-000, Brazil; \\ pi.teixeiradasilva@gmail.com (P.T.d.S.); thiagocrato@hotmail.com (T.S.d.F.); diniz.sena@urca.br (D.M.S.J.); \\ carlos.emidio@fisica.ufc.br (C.E.S.N.); hdmcoutiinho@urca.br (H.D.M.C.); \\ antoniolinkoln@ufpi.edu.br (A.L.A.B.L.); alexandre.teixeira@urca.br (A.M.R.T.) \\ 2 Centro de Ciências Exatas e Tecnologia, Curso de Química, Universidade Vale do Acaraú, \\ Sobral CE 62.040-370, Brazil; bandeira@uvanet.br (P.N.B.); murilo.sergio@uvanet.br (M.S.d.S.J.) \\ 3 Grupo de Química Teórica e eletroquímica, Faculdade de Filosofia Dom Aureliano Matos, FAFIDAM, \\ Universidade Estadual do Ceará, Limoeiro do Norte CE 62.930-000, Brazil; emmanuel.marinho@uece.br \\ 4 Departamento de Química Analítica e Físico-Química, Universidade Federal do Ceará, \\ Fortaleza CE 60.440-900, Brazil; aalinealcanfor@gmail.com (A.A.C.A.); \\ emanuellemarinho@gmail.com (E.M.M.); pln@ufc.br (P.d.L.-N.) \\ 5 Departamento de Física, Universidade Regional do Cariri, Crato CE 63.041-145, Brazil \\ 6 Departamento de Parasitologia e Microbiologia, Universidade Federal do Piauí, Teresina PI 64.049-550, \\ Brazil; hmbarreto@ufpi.edu.br \\ 7 Faculty of Medicine, University of Porto, Alameda Prof. Hernâni Monteiro, 4200-319 Porto, Portugal \\ 8 Institute for Research and Innovation in Health (i3S), University of Porto, 4200-135 Porto, Portugal \\ 9 Centro de Ciências e Tecnologia, Universidade Estadual do Ceará, Fortaleza CE 60.714.903, Brazil \\ * Correspondence: ncmartins@med.up.pt (N.M.); helcio.silva@uece.br (H.S.d.S.)
}

Received: 8 June 2020; Accepted: 2 July 2020; Published: 8 July 2020

\begin{abstract}
Background: Chalcones are part of a family of small phenolic compounds that are being extensively studied for presenting a diversity of molecular structures and biological activities. In this paper, two chalcones, (E)-1-(2-hydroxy-3,4,6-trimethoxyphenyl)-3-(3-nitrophenyl)prop-2-en-1-one (1), (E)-1-(2-hydroxy-3,4,6-trimethoxyphenyl)-3-(4-nitrophenyl)prop-2-en-1-one (2), were synthesized by Claisen-Schmidt condensation. Methods: The molecular structures of these chalcones were determined by Nuclear Magnetic Resonance and characterized by infrared, Raman spectroscopy, and electrochemical analysis at room temperature. Vibrational wavenumbers were predicted using Functional Density Theory (DFT) calculations, and their normal modes were analyzed in terms of potential energy distribution (PED). Besides this, DFT calculations were performed to obtain the molecular orbitals and their quantum descriptors. The UV-Vis absorption spectrum of the synthesized chalcones was measured and compared with each other. In addition, analyses of antimicrobial activity and modulation of antibiotic resistance were carried out to assess the antibacterial potential of these chalcones. Results: The vibrational spectra of polycrystalline chalcones obtained by ATR-FTIR, FT-Raman and DFT calculations allowed a complete assignment of the vibrational modes, and revealed the quantum chemical parameters. Both chalcones did not show good responses when associated with the antibiotics Ciprofloxacin and Cephalexin against S. aureus 10 and E. coli 06 strains. However, a significant potentiating of the Gentamicin activity against S. aureus 10 and E. col 06 strains was observed for chalcone 2. On the other hand, when associated with Norfloxacin, an antagonistic effect
\end{abstract}


was observed. The results found for EtBr suggest that, although the tested chalcones behave as efflux pump inhibitors, probably inhibiting other efflux pumps, they were not able to inhibit NorA. Thus, these synthetic chalcones are not recommended for use in association with Norfloxacin against strains of S. aureus 1199-B that overexpress the NorA gene. Conclusions: Spectroscopic data confirmed the structure of the chalcones, and chalcone 2 showed potential as an adjuvant in antibiotic therapy.

Keywords: chalcones; NMR; UV-VIS; FT-Raman; ATR-FTIR; electrochemical; DFT; antibacterial activity

\section{Introduction}

Chalcones are small open-chain flavonoids that present a wide range of structural properties with biochemical and pharmacological relevance [? ]. Chalcones and their derivatives have been extensively studied due to their relatively simple chemical structure, numerous substitution patterns with different functional groups, and endless biological activities associated with their structural and molecular diversity [? ? ? ? ? ? ? ]. The wide variety of activities that chalcones present include anticancer [? ? ], neuroprotective [? ], antimalarial [? ], anti-HIV [? ], antioxidant [? ? ], antibacterial [? ? ], and antileishmanial [? ] activities, among others.

Recently, an article was published on the spectroscopic characterization and evaluation of the antimicrobial activity and potentiators of the antibacterial effect of chalcone $\left(\mathrm{C}_{18} \mathrm{O}_{5} \mathrm{H}_{18}\right)$ [? ] derived from the natural product 2-hydroxy-3,4,6-trimethoxyacetophenone isolated from Croton anisodontus (Figure ??) [?]. The data obtained in this study showed that the chalcone is more reactive and lipophilic than its precursor molecule. Besides this, it has better antimicrobial potential than the molecule [? ]. These results agree with other studies with natural and synthetic chalcone derivatives, which have significant antibacterial activity against Gram-positive and Gram-negative bacteria [? ? ? ]. In addition, the potentiating effect of the action of different classes of antibiotics associated with natural and synthetic compounds has been shown to be capable of reducing the resistance of pathogenic bacteria [? ?].

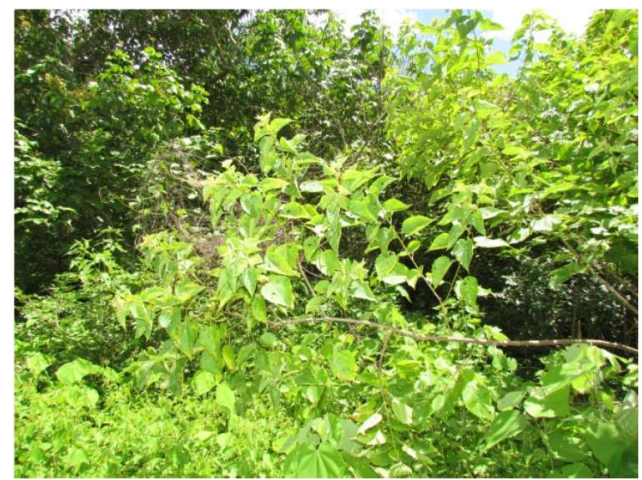

(a)

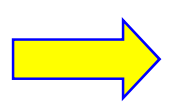<smiles>COc1cc(OC)c(C(C)=O)c(O)c1OC</smiles>

(b)

Figure 1. Aerial parts of C. Anisodontus (a) 2-hydroxy-3,4,6-trimethoxyacetophenone (b).

The intensive use of antibacterial agents for both medical and non-medical purposes has accelerated the development of multidrug-resistant bacteria [? ]. Consequently, there is an urgent need for the development of new antibacterial agents, as well as agents capable of inhibiting the mechanisms of resistance to antibiotics of traditional use [? ? ]. In this context, the synthesis of chalcones and their biologically active derivatives may allow the discovery of new, and more selective substances that may be useful as adjuvants in antibiotic therapy [? ]. Therefore, this study had evaluating the antimicrobial 
activity of two synthetic chalcones and their potential as a modifier of the antibacterial activity when associated with different antibiotics as its objective.

\section{Results and Discussion}

\subsection{NMR Data}

In the ${ }^{1} \mathrm{H}$ NMR spectrum (Table ??), a signal observed in $\delta_{\mathrm{H}} 3.90,3.97$, and $3.98 \mathrm{ppm}$, referring to hydrogen from the methoxy groups. In $\delta_{\mathrm{H}} 7.75(J=15.60)$ and $7.94(J=15.60)$ are assigned to two doubles referring to unsaturated hydrogen $\alpha, \beta$, whose coupling constant $(J)$ confirms the stereochemical trans of the double bond. The singlet observed in $6.04 \mathrm{ppm}$ refers to hydrogen-bonded to a carbon $5^{\prime}$ of ring A. The singlet in $8.45 \mathrm{ppm}$ refers to $\mathrm{H}-2$, the signal in $7.59 \mathrm{ppm}$ corresponds to $\mathrm{H}-5$, whereas the signals in $8.22(\mathrm{~d}, J=8.13 \mathrm{~Hz})$ and $7.86(\mathrm{~d}, J=7.60 \mathrm{~Hz})$ refer to $\mathrm{H}-4$ and $\mathrm{H}-6$, respectively. In the ${ }^{1} \mathrm{H}$ NMR spectrum, the signals in 3.90, 4.02, and $4.10 \mathrm{ppm}$ referring to methoxyl hydrogen can be observed. In $8.33(J=16.1)$ and $8.36(J=15.4)$ are attributed to two doubles referring to unsaturated hydrogen $\alpha, \beta$, whose coupling constant $(J)$ confirms the stereochemical $E$ of the double bond. The singlet observed in 6.04 refers to hydrogen attached to the carbon $5^{\prime}$ of ring A. The signals at $8.09(\mathrm{~d}, J=8.09 \mathrm{~Hz})$ and $7.69(\mathrm{~d}, J=8.1 \mathrm{~Hz})$ refer to $\mathrm{H}-3 / 5$ and $\mathrm{H}-2 / 6$, respectively.

Table 1. ${ }^{1} \mathrm{H}$ and ${ }^{13} \mathrm{C}$ NMR data from chalcones 1 and 2 in $\mathrm{CDCl}_{3}$. The chemical displacements in ${ }^{13} \mathrm{C}$ and ${ }^{1} \mathrm{H}$ are in ppm.

\begin{tabular}{ccccc}
\hline & \multicolumn{2}{c}{$\mathbf{1}$} & \multicolumn{2}{c}{$\mathbf{2}$} \\
\hline $\mathbf{C}$ & $\boldsymbol{\delta}_{\mathbf{C}}$ & $\boldsymbol{\delta}_{\mathbf{H}}$ & $\boldsymbol{\delta}_{\mathbf{C}}$ & $\boldsymbol{\delta}_{\mathbf{H}}$ \\
\hline $1^{\prime}$ & 106.9 & & 106.9 & \\
$2^{\prime}$ & 158.9 & & 158.8 & \\
$3^{\prime}$ & 131.1 & & 131.2 & \\
$4^{\prime}$ & 159.6 & & 159.6 & \\
$5^{\prime}$ & 87.2 & $6.02(\mathrm{~s})$ & 87.4 & $6.04(\mathrm{~s})$ \\
$6^{\prime}$ & 159.2 & & 159.1 & \\
$\mathrm{MeO}-3^{\prime}$ & 60.9 & $3.84(\mathrm{~s})$ & 60.9 & $3.90(\mathrm{~s})$ \\
$\mathrm{MeO}-4^{\prime}$ & 56.3 & $3.97(\mathrm{~s})$ & 56.4 & $4.02(\mathrm{~s})$ \\
$\mathrm{MeO}-6^{\prime}$ & 56.2 & $3.98(\mathrm{~s})$ & 56.3 & $4.10(\mathrm{~s})$ \\
$\mathrm{C}=\mathrm{O}$ & 192.7 & & 192.7 & \\
1 & 137.5 & & 137.6 & \\
2 & 122.3 & & 122.3 & $8.09(\mathrm{~d}, J=8.09 \mathrm{~Hz})$ \\
3 & 148.9 & & 124.4 & $7.69(\mathrm{~d}, J=8.1 \mathrm{~Hz})$ \\
4 & 124.4 & $8.22(\mathrm{~d}, J=8.13 \mathrm{~Hz})$ & 149.0 & \\
5 & 130.1 & $7.59(\mathrm{t})$ & 130.1 & $7.69(\mathrm{~d}, J=8.1 \mathrm{~Hz})$ \\
6 & 134.5 & $7.86(\mathrm{~d}, J=7.60 \mathrm{~Hz})$ & 134.4 & $8.09(\mathrm{~d}, J=8.09 \mathrm{~Hz})$ \\
$\mathrm{C} \alpha$ & 130.6 & $7.75(\mathrm{~d}, J=15.60 \mathrm{~Hz})$ & 130.7 & $8.33(\mathrm{~d}, J=16.1 \mathrm{~Hz})$ \\
$\mathrm{C} \beta$ & 139.6 & $7.94(\mathrm{~d}, J=15.60 \mathrm{~Hz})$ & 139.3 & $8.36(\mathrm{~d}, J=15.4 \mathrm{~Hz})$ \\
\hline
\end{tabular}

In the ${ }^{13} \mathrm{C}$ NMR spectrum (Table ??), the $\delta_{\mathrm{C}} 192.7 \mathrm{ppm}$ signal is assigned to the carbonyl group in the $\alpha, \beta$ unsaturated (enone) system. Ketone free carbonyl absorbs in 203.8. However, the presence of $\alpha, \beta$ unsaturation causes displacement in the signal position due to the decreased double character of the bond $(\mathrm{C}=\mathrm{O})$ [? ]. Olefin carbons $\alpha$ and $\beta$ are observed at 130.6 and $139.6 \mathrm{ppm}$, respectively. The signals at 60.956 .3 and $56.2 \mathrm{ppm}$ refer to methoxyl carbons. At $159.6\left(\mathrm{C}-4^{\prime}\right), 159.2\left(\mathrm{C}-6^{\prime}\right), 158.9\left(\mathrm{C}-2^{\prime}\right)$, $131.1\left(\mathrm{C}-5^{\prime}\right), 106.9\left(\mathrm{C}-1^{\prime}\right), 87.2\left(\mathrm{C}-3^{\prime}\right) \mathrm{ppm}$, the signals for carbons are present in ring $\mathrm{A}$, while carbons 1 to 6 present in ring B can be observed at 148.9 (C-3), 137.5 (C-1), 134.5 (C-6), 130.1 (C-5), 124.2 (C-4) and 122.3 (C-2) ppm (Figures S1-S4, see supplementary material). 


\subsection{Molecular Structure}

Figure ?? shows the molecular structure of the chalcones. These structures are in accordance with our NMR data reported in Table ??. The basic structure of the chalcones comprises two six-member aromatic rings. Ring $\mathrm{A}$ is formed by atoms $\mathrm{C}^{\prime}, \mathrm{C}^{\prime}, \mathrm{C}^{\prime}, \mathrm{C}^{\prime}, \mathrm{C}^{\prime}$ and $\mathrm{C}^{\prime}$, and ring $\mathrm{B}$ is formed by atoms $\mathrm{C} 1, \mathrm{C} 2, \mathrm{C} 3, \mathrm{C} 4, \mathrm{C} 5$, and $\mathrm{C} 6$. These two aromatic rings are joined by an unsaturated three-carbon carbonyl system $\left(C-C \alpha=C_{\beta}\right)$. Therefore, these molecular structures are characteristics of chalcones [? ? ].
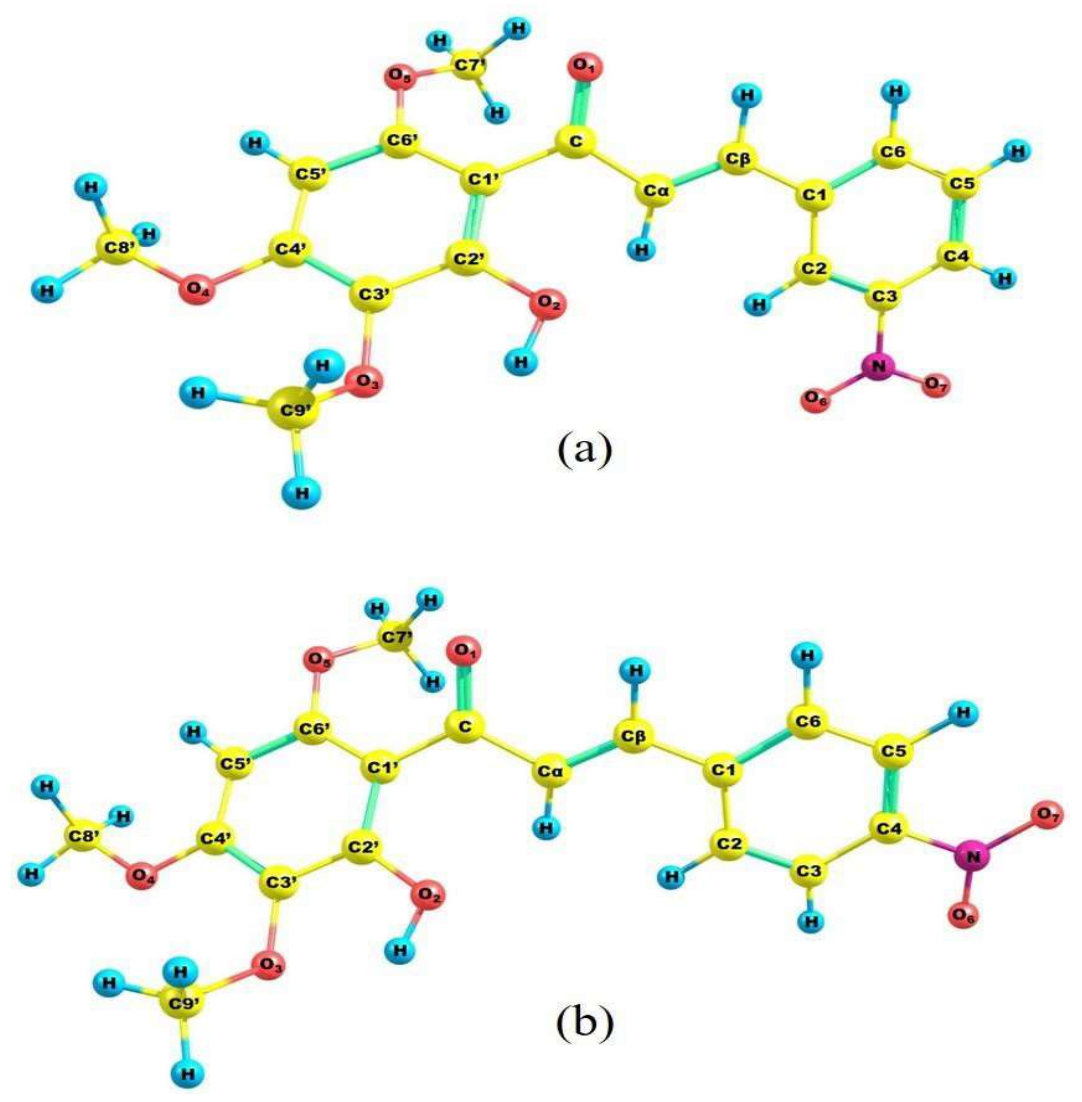

Figure 2. Molecular structure in the ball and stick model with the numbering of atoms for chalcone 1 (a) and 2 (b).

\subsection{Electrochemical Analysis}

The cyclic voltammograms obtained by chalcones are shown in Figure ??. For chalcone 1 (Figure ??a), a broad shoulder located around $0.70 \mathrm{~V}$ is noted (forward scan), and it is related to the electrochemical oxidation of chalcone 1 . For chalcone 2 (Figure ??b), two broad shoulders, one around $0.4 \mathrm{~V}$ and the other about $0.95 \mathrm{~V}$, are displayed in the forward scan, and one peak located around 0.35 $\mathrm{V}$ appears in the reverse scan. In Figure ??b, the process about 0.4 is related to the oxidation of the chalcone 2, and the one around 0.95 is attributed to the second oxidation process of the chalcone 2 molecule and, finally, the process observed in the reverse scan of about 0.35 is attributed to the reduction in the products formed in the forward scan. The fact that the potential related to the electrochemical oxidation of the chalcone $2(0.40 \mathrm{~V})$ is less positive than the corresponding potential for chalcone 1 $(0.70 \mathrm{~V})$ shows that chalcone 2 requires less energy to be oxidized, which means that the chalcone 2 has an electrophilic character in comparison to chalcone 1. 

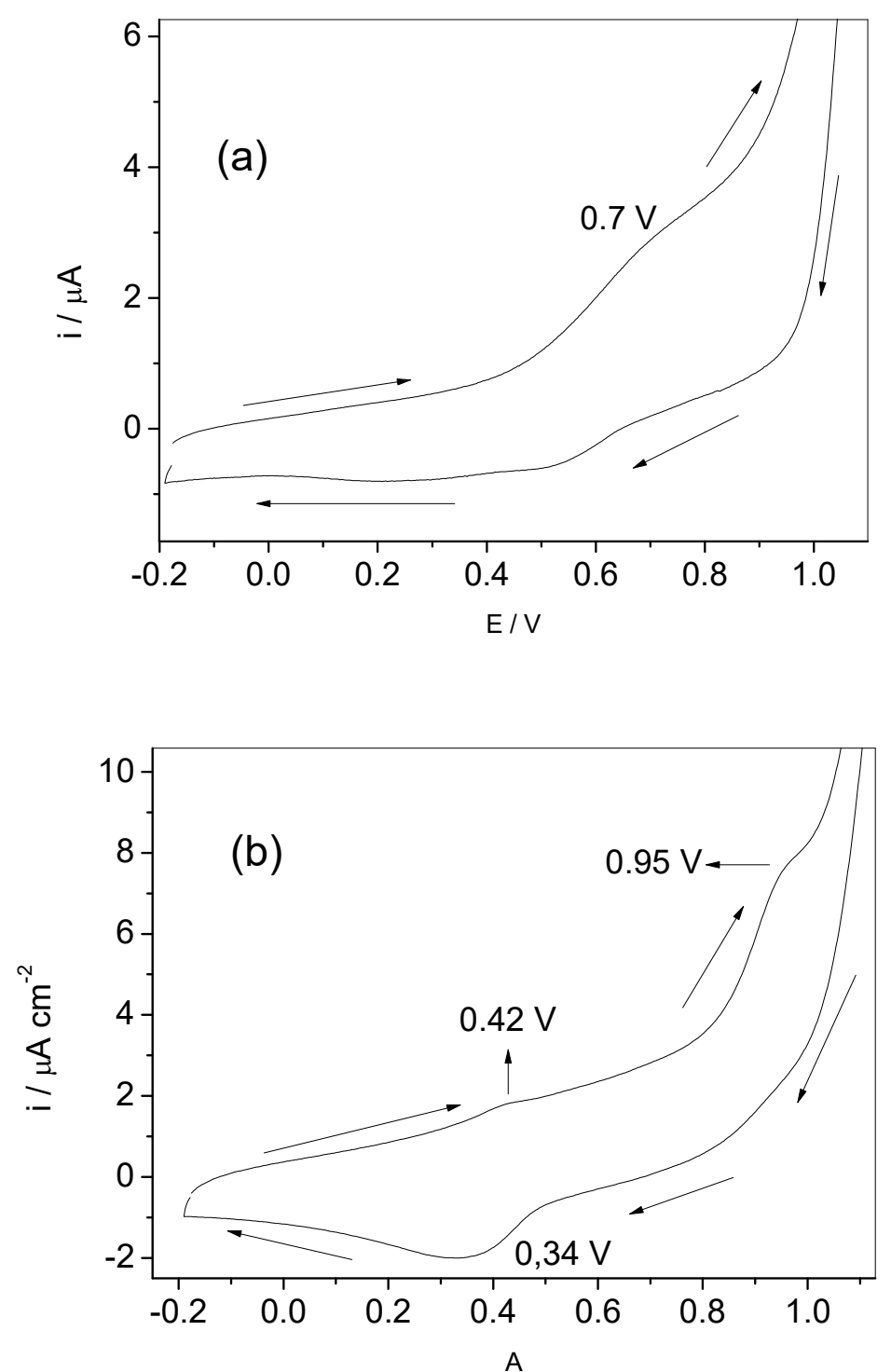

Figure 3. Cyclic voltammograms obtained for chalcone 1 (a) and 2 (b) in dichloromethane at $50 \mathrm{mV} \mathrm{s}^{-1}$ and at room temperature $\left(\cong 25^{\circ} \mathrm{C}\right)$.

\subsection{Quantum Chemical Parameters}

The molecular orbital frontier theory developed by Kenichi Fukui in the 1950s plays a key role in the understanding of chemical reactivity [? ]. HOMO is the most external orbital that contains electron donors, and LUMO is the most internal orbital that contains free places to accept electrons. The chemical behavior of the chalcones can be predicted by the following parameters: HOMO energy, LUMO energy, energy difference $(\triangle \mathrm{E}=-\mathrm{ELUMO}-\mathrm{EHOMO})$, vertical ionization energy (I-EHOMO), vertical affinity of electrons $(A=-E L U M O)$, chemical potential $(\mu=-(I+A) / 2)$, electronegativity $(\eta=-\mu)$, overall hardness $(\eta=(I-A) / 2)$ and electrophilicity index $\left(\omega=\mu^{2} / 2 \eta\right)$ [? ? ? ]. These quantum chemical parameters for the optimized geometries of the substances and the graphical structures of the molecular orbitals (Table ??).

Table 2. Quantum chemical parameters for optimized geometries of chalcones in (eV).

\begin{tabular}{cccccccccc}
\hline Chalcone & EHOMO & ELUMO & $\boldsymbol{\Delta E}$ & $\mathbf{I}$ & $\mathbf{A}$ & $\boldsymbol{\mu}$ & $\chi$ & $\boldsymbol{\eta}$ & $\boldsymbol{\omega}$ \\
\hline $\mathbf{1}$ & -5.74 & -2.44 & 3.30 & 5.74 & 2.44 & -4.09 & 4.09 & 1.65 & 5.07 \\
$\mathbf{2}$ & -5.83 & -2.76 & 3.07 & 5.83 & 2.73 & -4.30 & 4.30 & 1.54 & 6.00 \\
\hline
\end{tabular}


According to Figure ??, the aromatic ring A of the chalcones acts as an electron donor and the ring $\mathrm{B}$ acts as an electron acceptor, which was already expected, since the ring $\mathrm{A}$ has methoxy donor groups and the aromatic ring $B$ has nitro $\left(\mathrm{NO}_{2}\right)$ withdrawal groups with a different substitution pattern for the molecular structures of the chalcones. The values of the energy gap, hardness, and chemical potential in chalcone 2 are lower than the values found for chalcone 1 . Therefore, the reduction in these chemical parameters indicates that the reactivity of chalcone 2 is higher than that observed in chalcone 1 . Consequently, chalcone 2 has a better electrophilic character than chalcone 1 , as observed in the electrophilicity index values of these molecules $(6.00 \mathrm{eV}$ for chalcone 2 versus $5.07 \mathrm{eV}$ for chalcone 1$)$. A possible explanation for this result can be attributed to the nature of the intramolecular charge transfer by the resonance effect between nitrogen and the two oxygen atoms of its structure and by the difference in the pattern of target substitution and for oriented nitro groups present [? ? ].

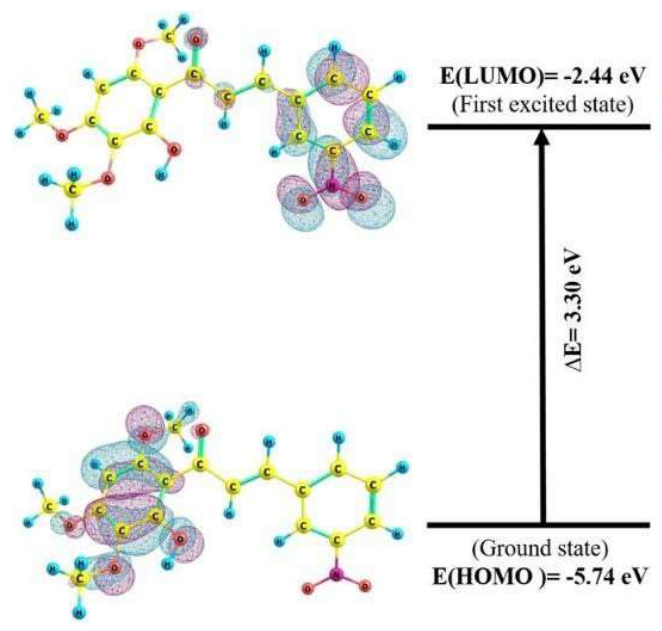

(a)

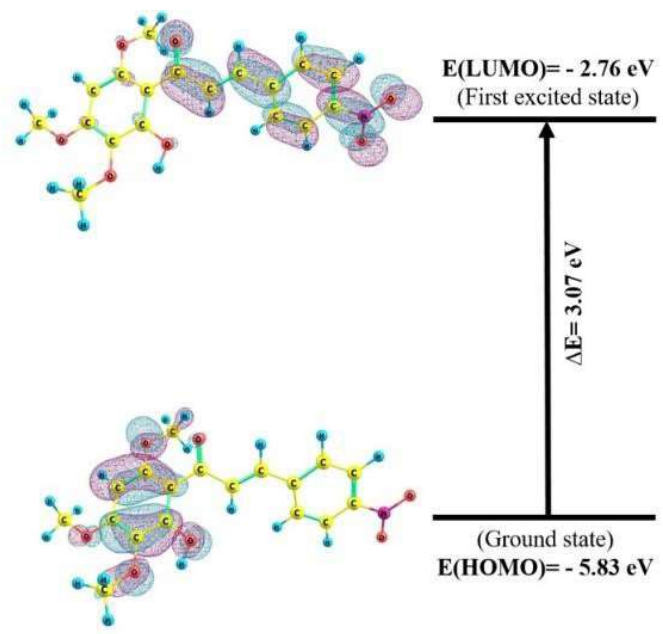

(b)

Figure 4. HOMO and LUMO molecular orbitals for chalcone 1 (a) 2 (b).

For the chalcone 1, the electron removal effect of the $\mathrm{NO}_{2}$ group acts on the pi electrons $(\pi)$ in the $\mathrm{B}$ ring leaving the oxygen with higher charge density, which leads to an increase in the electronic polarizability of the $\mathrm{NO}_{2}$ group and, consequently, a decrease in the polarizability of the connections with the rest of the structure. For the chalcone 2, the nature of the intramolecular charge transfer occurs more easily due to the fact that it has a flatter structure than the chalcone 1, thus allowing greater conjugation and displacement of the system $\pi \pi \pi^{*}$ (of the HOMO and LUMO orbitals) than with the carbonylic system $(\mathrm{C}=\mathrm{C}-\mathrm{C}=\mathrm{O})$ caused by a possible resonance effect, as can be seen in Figure ??b. It is worth remembering that ring $\mathrm{A}$ of the chalcones is made up of electron donor groups and can influence the stability and/or reactivity of each molecule.

The experimental UV absorption spectra of the chalcones in ethanol solution are shown in Figure ??. From the analysis of the spectra, it is possible to observe two very characteristic bands in the region of the ultra-violet, one of higher energy, $(340 \mathrm{~nm})$ attributed to transitions $\mathrm{n} \rightarrow \pi^{*}$ of the aromatic ring $\mathrm{B}$ for the $\mathrm{NO}_{2}$ group, and the other of lesser energy in the region of the visible $(407 \mathrm{~nm})$ attributed to transitions $\pi \pi \pi^{*}$ of the system $\mathrm{C} \alpha=\mathrm{C} \beta-\mathrm{C}=\mathrm{O}$ for the $\mathrm{NO}_{2}$ of the chalcone 2 . The maximum wavelengths, $\lambda \max$ for chalcones 1 and 2, correspond to the energy values of 3.65 and $3.05 \mathrm{eV}$, respectively. These values corroborate the values calculated from the energy difference between the HOMO and the LUMO, within a percentage error of $9.6 \%$, and $0.7 \%$, respectively. 


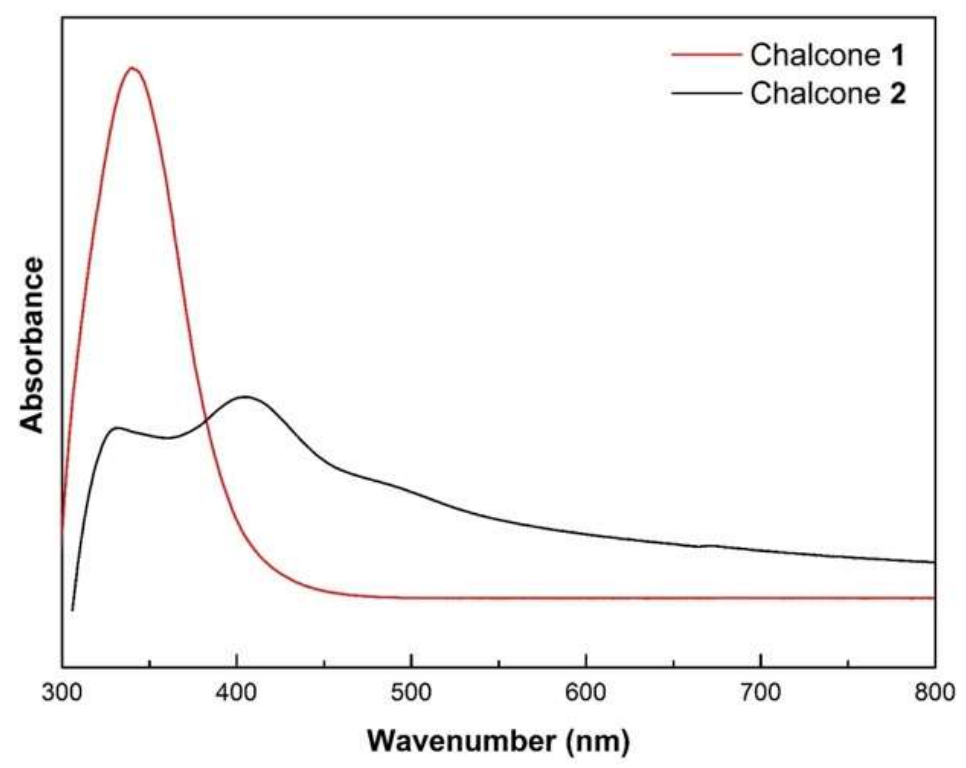

Figure 5. UV-Vis experimental spectra of chalcones 1 and 2 in ethanol solution.

\subsection{Vibrational Analysis}

The chalcones have the molecular formula $\mathrm{C}_{18} \mathrm{H}_{17} \mathrm{NO}_{7}$, and therefore have 43 atoms, allowing 129 degrees of freedom (3N). Therefore, 123 vibrational modes are expected, excluding the three rotation movements and the three translation movements (3N-6). The experimental spectra of FT-Raman of polycrystalline samples of the chalcones are shown in Figure ??, while the experimental ATR-FTIR spectra of these substances are shown in Figure ??. The complete attribution of all theoretical and staggered vibration modes, associated with the wavenumbers observed in the experimental spectra of FT-Raman and ATR-FTIR of the chalcones 1 and 2, respectively, are presented in Tables S1 and S2. In each table, the first and second columns correspond to the calculated (wcalc) and staggered (wscal) wavenumbers, respectively. The third and fourth columns correspond to the experimental wave numbers of the FT-Raman $\left(\omega_{\text {Raman }}\right)$ and ATR-FTIR $\left(\omega_{\text {FTIR }}\right)$ spectra, respectively, and the fifth column shows the assignment of vibration modes along with the contribution of potential energy distribution (PED), with values higher than $10 \%$ for each vibration mode. The FT-Raman (Figure ??) and ATR-FTIR spectra (Figure ??) for chalcones 1 and 2 samples present many bands that coincide with those already reported in the literature for chalcones [? ], which is expected, since, in these chalcones, the change that occurs is in the B-ring substitution pattern of these derivatives of the natural product 2-hydroxy-3,4,6-trimethoxyacetophenone.

The assignment for the chalcones 1 and 2 shows that most of the bands observed through FT-Raman and FT-IR spectroscopy (Bruker, Billerica, MA, USA) correspond to a mixture of vibrational modes. In addition, there is a good match between the staggered and experimental Raman and infrared bands. In the step wavenumber region of the Raman and infrared spectra of $14-960 \mathrm{~cm}^{-1}$ of the vibrational spectra, the presence of torsion modes, out-of-plane deformations, and deformations in the carbon atoms of the aromatic rings and their ligands, as well as of the $\mathrm{NO}_{2}$ groups, predominates. It should be considered that modes below $100 \mathrm{~cm}^{-1}$ are associated with external modes, which were not computed because the DFT calculations were performed on isolated molecules, and therefore do not consider the periodicity of the crystalline network. 


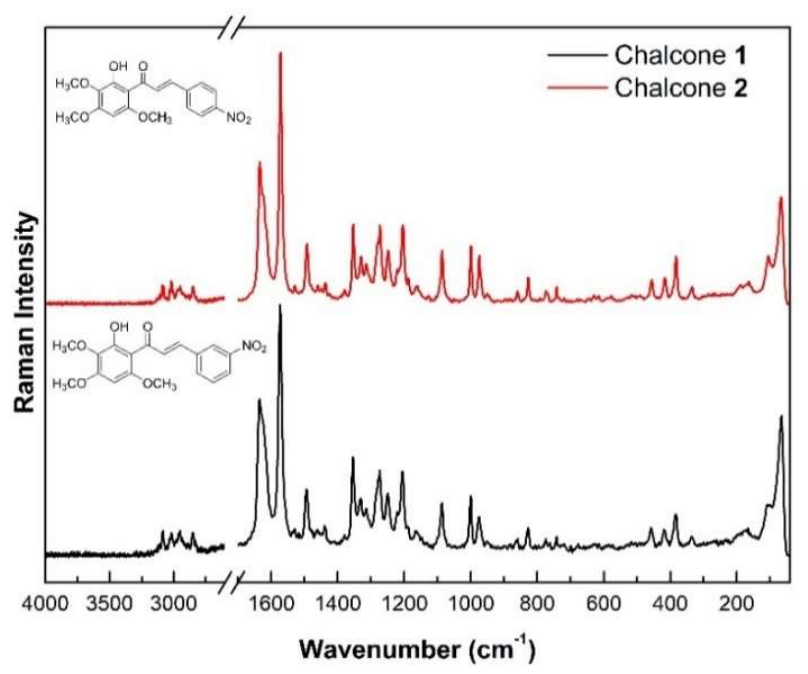

Figure 6. Experimental FT-Raman spectra of chalcones 1 and 2.

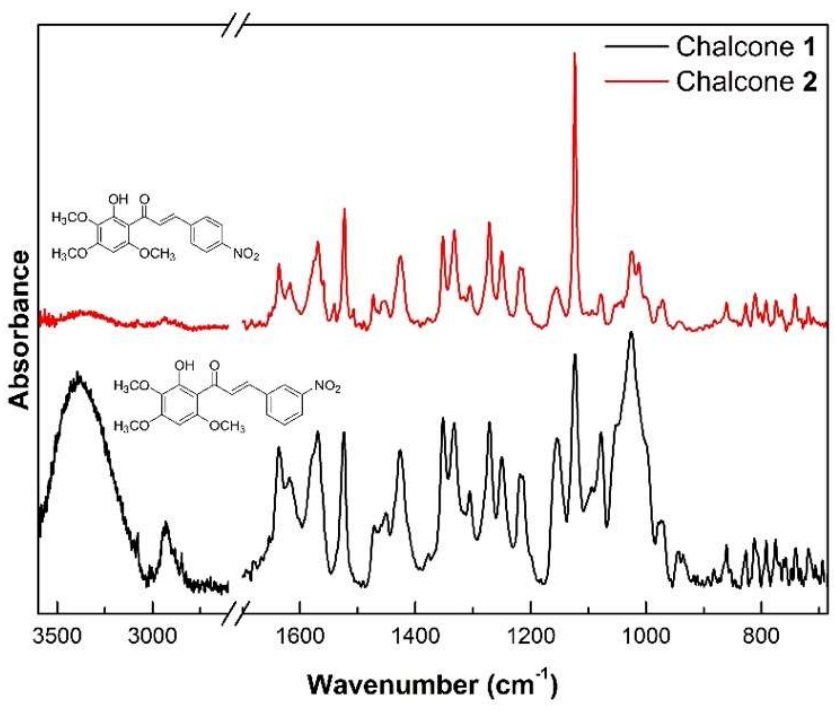

Figure 7. Experimental spectra of ATR-FTIR of the chalcones 1 and 2.

The chalcones 1 and 2 ATR-FTIR spectra show more intense absorbance bands in the range from $670-1700 \mathrm{~cm}^{-1}$. The absorbance bands between 960 and $1671 \mathrm{~cm}^{-1}$ of the Raman and infrared spectra consist mainly of the stretching modes $\mathrm{CC}, \mathrm{CO}, \mathrm{CN}$, and $\mathrm{NO}$ and deformations of the HCC, $\mathrm{CCO}$, and $\mathrm{ONO}$ atoms. It is noted that the intensities of the most infrared bands in the region between 1200 and $1000 \mathrm{~cm}^{-1}$ are more intense in the chalcone 1 than those observed in the chalcone 2 . The differences in the infrared intensities are expected, since this spectral region is within the fingerprint region, which is unique to each one of those chalcones. As the chalcones 1 and 2 are polycrystalline, their molecules are periodically arranged in their crystals. It is known that the intermolecular interactions in molecular crystal depend on how the packing of molecules is arranged within its unit cell, and how the electronegativity affects the intermolecular forces [? ? ]. Since the chalcone 2 has higher electronegativity than chalcone 1 , it has intermolecular interactions that are more intense than the chalcone 1 ( $4.30 \mathrm{eV}$ for chalcone 2 against $4.09 \mathrm{eV}$ for chalcone 1 ). The values of the electronegativity $(\chi)$ were calculated by the expression $\chi=(\mathrm{I}+\mathrm{A}) / 2$, where $\mathrm{I}$ is the vertical ionization energy that is equal to minus the energy of the $\mathrm{HOMO}\left(\mathrm{I}=-\mathrm{E}_{\mathrm{HOMO}}\right)$, and $\mathrm{A}$ is vertical electron affinity that is equal to minus the energy of the LUMO ( $\left.\mathrm{A}=-\mathrm{E}_{\mathrm{LUMO}}\right)$ [? ]. Variations in the intermolecular interactions produce changes in the dipole moment during the vibration, and therefore affect the infrared bands. In crystals, the infrared bands tend to be more intense when the fingerprinting intermolecular interactions are 
weak [? ]. For this reason, as chalcone 2 has stronger fingerprinting intermolecular interactions than chalcone 1 , it is expected that the infrared bands have lower intensities when compared with those of the chalcone 1. Moreover, in this region, it is possible to observe deformation modes of the methyl groups. In fact, wagging vibrations and asymmetric deformations in the methyl groups are clearly observed in these substances between 1426 and $1490 \mathrm{~cm}^{-1}$, as well as in the HYTPHENYL chalcone [? ]. The presence of the target and substituted nitro groups caused subtle displacements in these vibrational modes among themselves, and, when compared with HYTPHENYL, due to the effect of removing electrons from this group, which causes a displacement of electronic density and consequently a variation in the intensity and region of vibrational, assisted in the differentiation of the spectrum for chalcones 1 and 2 .

The carbonyl stretching modes $(\mathrm{C}=\mathrm{O} 1)$ for chalcones are in the range of 1594 to $1671 \mathrm{~cm}^{-1}$. In both spectra, it is possible to observe that the stretching modes $\mathrm{C}=\mathrm{O} 1$, of carbonyl, are associated with the stretching modes $\mathrm{NO}, \mathrm{CC}$, and $\mathrm{C} \alpha \mathrm{C} \beta$, being in infrared observed in $1618 \mathrm{~cm}^{-1}$ and $1636 \mathrm{~cm}^{-1}$ for the chalcones, respectively. It is worth mentioning that the stretching modes $\mathrm{C}=\mathrm{O} 1$ in the infrared spectra have a lower intensity than those observed in other classes of organic compounds. In addition, the presence of different functional groups can cause displacements in and characteristic intensities for each sample [?].

In the region with a scaled wavenumber greater than $2913 \mathrm{~cm}^{-1}$ present, the molecular vibrations are associated with the symmetrical and asymmetrical stretching modes of the $\mathrm{CH}, \mathrm{CH}$, and $\mathrm{OH}$ groups of the chalcones as well as those of the HYTPHENYL chalcone [? ]. It is noteworthy that the stretching modes of the $\mathrm{OH}$ hydroxyl in the infrared spectra have a lower intensity in the chalcone 2 than those observed in the chalcone 1 . This effect is expected, since the intensity of the $\mathrm{OH}$ stretching band can increase when hydroxyl group is forming a hydrogen bond [? ].

A complete description of all the modes that appear in the Raman and infrared spectra of the chalcones 1 and 2 is provided in Tables S5 and S6 (see supplementary material), respectively. In the experimental spectra of FT-Raman, the bands with higher absorption were related to the symmetrical and asymmetrical stretching modes of the $\mathrm{NO}_{2}$ groups. The effect on the higher intensity of these bands is due to the presence of $\mathrm{NO}_{2}$ groups' increasing polarizability (inducing a potential resonant effect among the oxygen directly linked to it) in these structures, which is more easily detected by the FT-Raman technique.

\subsection{Antimicrobial and Modulating Activities of Antibiotics}

The results showed that the minimum inhibitory concentration (MIC) values obtained for chalcones 1 and 2 was $\geq 1024 \mu \mathrm{g} \mathrm{L}^{-1}$, meaning that the chalcones had no inhibitory action on bacterial growth at the highest concentration levels tested. Previous studies with chalcone derivatives have shown good antibacterial activity against Gram-positive and Gram-negative strains. However, these antibacterial activities are dependent on their pattern of structural replacement [? ? ? ? ? ]. When associated with Ciprofloxacin or Cephalexin, both chalcones 1 and 2 were not able to potentiate the antimicrobial activity of these antibiotics against multidrug-resistant strains S. aureus SA10 (Figure ??a,c) and E. coli EC06 (Figure ??a,c). However, the potentiating action of the chalcone 2 was observed when associated with Gentamicin against both strains. These results suggest that chalcone 2 is a compound candidate for a deep investigation into their benefits as an adjuvant of Gentamicin against multidrug-resistant S. aureus and E. coli strains. On the other hand, the addition of chalcone 1 to the growth medium resulted in an antagonistic action against both strains, increasing the MIC values the Gentamicin from 16 to $20.15 \mu \mathrm{g} \mathrm{mL}{ }^{-1}$ for S. aureus SA10 and from 32 to $256 \mu \mathrm{g} \mathrm{mL}^{-1}$ for E. coli EC06 (Figures ??b and ??b). 


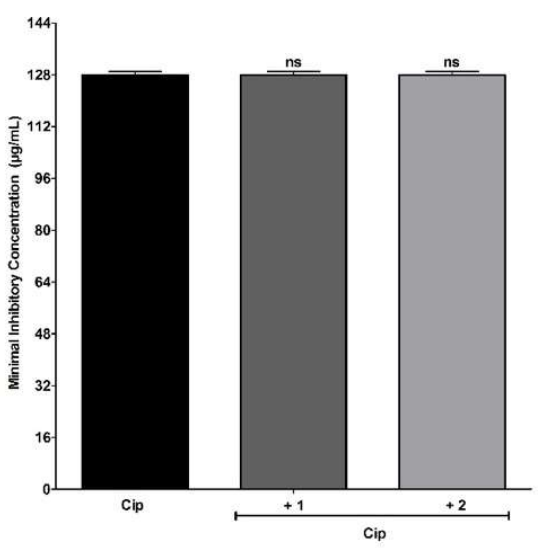

(a)

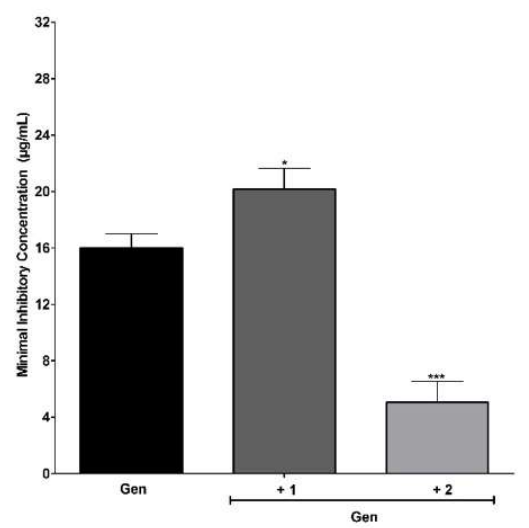

(b)

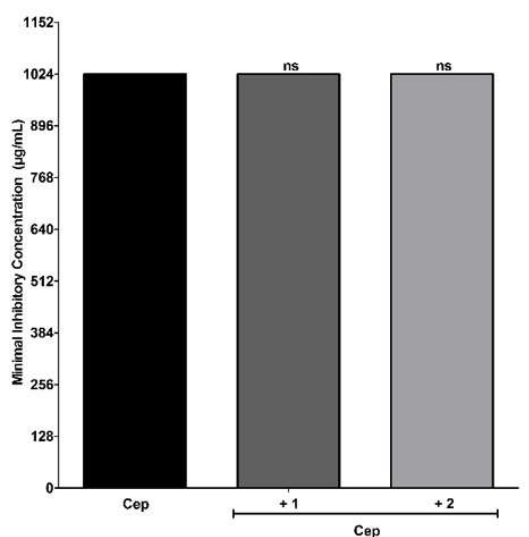

(c)

Figure 8. Minimum inhibitory concentration (MICs) of the Ciprofloxacin (Cip) (a), Gentamicin (Gen) (b), and Cephalexin (Cep) (c) in the absence or presence of the chalcones 1 and 2 at sub-inhibitory concentrations (MIC 1/8) against multidrug-resistant S. aureus SA10. Each result is the geometric mean of three simultaneous experiments. $\left.{ }^{* * *}\right)$ Statistically significant values $(p<0.0001) ;\left(^{*}\right)(p<0.05)$. 


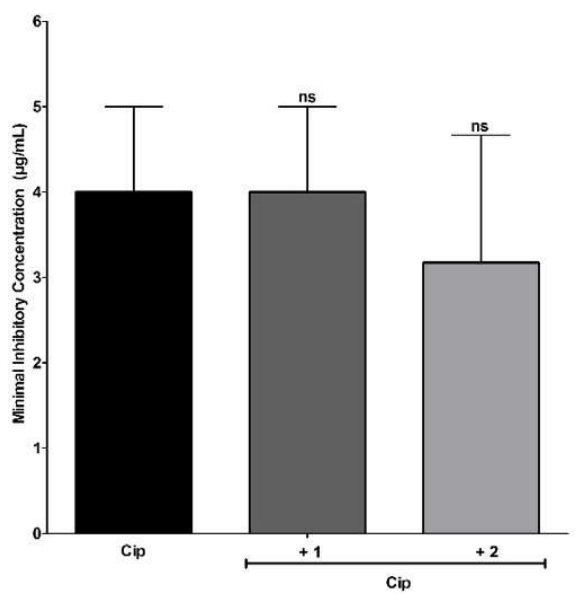

(a)

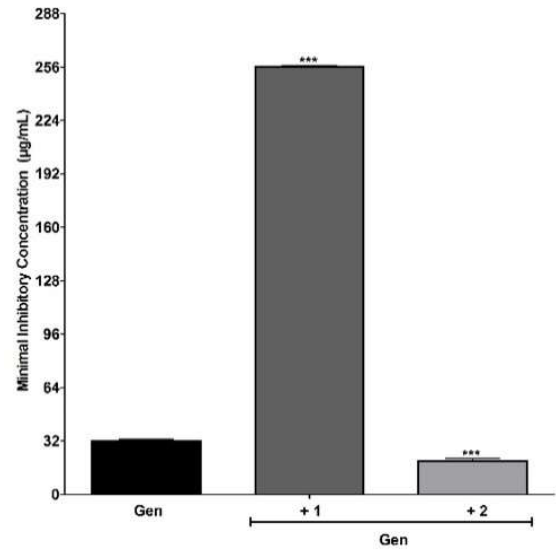

(b)

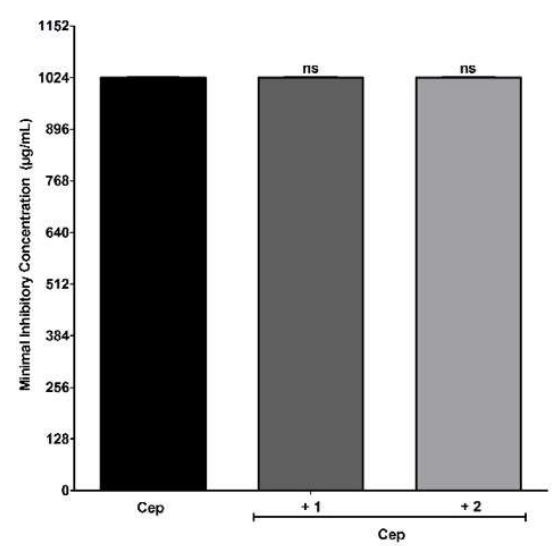

(c)

Figure 9. MICs of the Ciprofloxacin (Cip) (a), Gentamicin (Gen) (b), and Cephalexin (Cep) (c) in the absence or presence of the chalcones 1 and 2 at sub-inhibitory concentrations (MIC 1/8) against multidrug-resistant E. coli. Each result is the geometric mean of three simultaneous experiments. $\left.{ }^{* * *}\right)$ Statistically significant values $(p<0.0001)$.

Previous studies have reported that compounds with a nitro group, depending on their molecular structure, are potential therapeutic agents due to their mode of action involving the biotransformation of the nitro group, releasing intermediates in the redox process and causing changes in the stability of 
membrane structures of several microorganisms and cells [? ]. The computational chemical calculations showed that chalcone 2 has a greater electrophilic character than chalcone 1 due to the higher value of the electrophilicity index and the data obtained by the cyclic voltammetry of chalcones reveal that chalcone 2 undergoes the oxidation process before chalcone 1 , which indicates a greater electrophilic character and greater chemical reactivity. The higher reactivity and electrophilicity of the synthetic chalcone 2, can be responsible for intermediated interactions between the nitro group and the bacterial cell wall and, when combined with the gentamicin drug, proved to be more efficient. It is worth adding that the sensitivity profile of Gram-positive and Gram-negative bacteria to antibiotics is different, and the bacteria tested in the present study already had an intrinsic resistance profile to these antibiotics.

Chalcones 1 and 2 were able to modulate the resistance to $\mathrm{EtBr}$ in the strain SA1199B overexpressing the efflux pump NorA, indicating that both chalcones 1 and 2 could be efflux pump inhibitors (Figure ??a,b). However, when associated with Norfloxacin, an antagonism effect was observed. The results found for EtBr suggest that, although synthetic chalcones tested behave as efflux pump inhibitors, probably inhibiting other efflux pumps, they were not able to inhibit NorA and consequently were not recommended for use in association with Norfloxacin against $S$. aureus strains overexpressing the NorA gene.

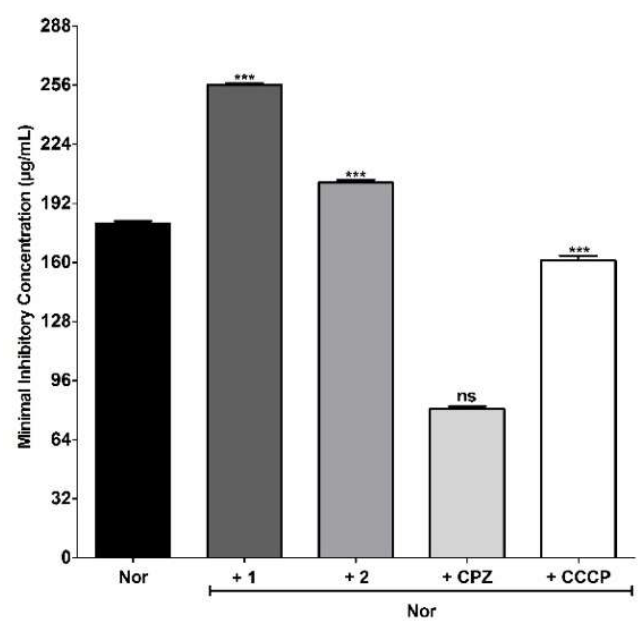

(a)

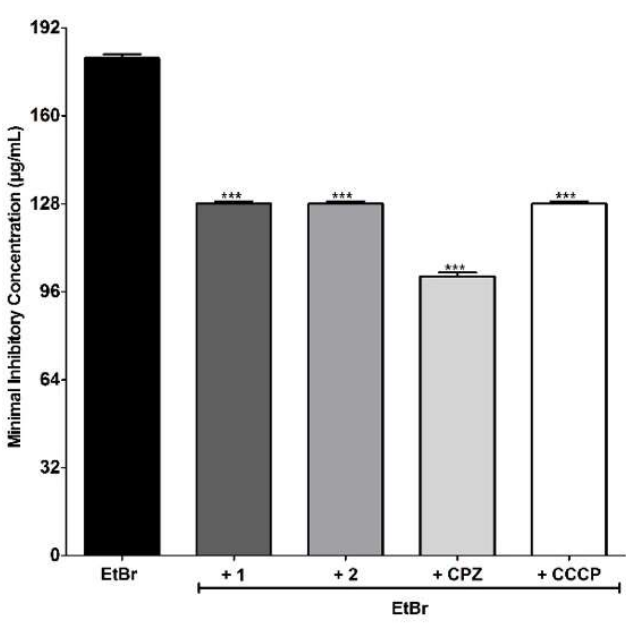

(b)

Figure 10. MICs of the Norfloxacin (Nor) (a) and Ethidium Bromide (EtBr) (b) in the absence or presence of the chalcones 1 and 2, as well as, Chlorpromazine (CPZ) and Carbonylcyanide m-chlorophenyl hydrazone (CCCP) at sub-inhibitory concentrations (MIC 1/8) against SA1199-B (norA). Each result is the geometric mean of three simultaneous experiments. $\left.{ }^{* * *}\right)$ Statistically significant values $(p<0.0001)$.

\section{Materials and Methods}

\subsection{Synthesis of Chalcones}

The description of the procedure of the synthesis of the chalcones is shown in Scheme ??. The chalcones $(1,2)$ were synthesized by a Claisen-Schmidt condensation reaction in basic medium. An ethanol solution of 2-hydroxy-3,4,6trimethoxyacetophenone ( $2 \mathrm{mmol})$ was added to a solution of nitro benzaldehyde ( $2 \mathrm{mmol}$ ), followed by the addition of 10 drops of $50 \% w / v$ aq. $\mathrm{NaOH}$ with stirring for $48 \mathrm{~h}$ at room temperature. The solid that formed was filtered under reduced pressure, washed with cold water, and analyzed by TLC. 
<smiles>COc1cc(OC)c(C(C)=O)c(O)c1OC</smiles><smiles>[R]c1ccc(C=O)cc1[R]</smiles><smiles>[R]c1ccc(/C=C/C(=O)c2c(OC)cc(OC)c(OC)c2O)cc1[R]</smiles>

$$
\begin{aligned}
& 1 \mathrm{R}_{1}=\mathrm{NO}_{2} \mathrm{R}_{2}=\mathrm{H} \\
& 2 \mathrm{R}_{1}=\mathrm{HR}_{2}=\mathrm{NO}_{2}
\end{aligned}
$$

Scheme 1. Preparation of chalcones a) $\mathrm{NaOH} 50 \% w / v$, ethanol, r.t., 48 h.

\section{2. $N M R$}

The ${ }^{1} \mathrm{H}$ and ${ }^{13} \mathrm{C}$ NMR were obtained using the Bruker spectrometer, model Advance DRX-500 ( ${ }^{1} \mathrm{H}$ NMR: $500 \mathrm{MHz}$ and ${ }^{13} \mathrm{C}$ NMR: $125 \mathrm{MHz}$, Bruker, Billerica, Mass., United States), using deuterated chloroform $\left(\mathrm{CDCl}_{3}\right)$ as the solvent. Chemical displacements are observed as values $\delta$ in parts per million (ppm) in relation to the solvent.

\subsection{FT-Raman and ATR-FTIR}

The Raman spectra with Fourier transform (FT-Raman) were obtained using a Bruker FTR system RFS100/S and a D418-T detector (Bruker, Billerica, MA, USA), with an Nd: YAG laser, with a nominal power of $150 \mathrm{~mW}$, emitting in the laser line $1064 \mathrm{~nm}$ as the excitation source. The spectra were recorded at room temperature in the region of 40 to $4000 \mathrm{~cm}^{-1}$ with a resolution of $4 \mathrm{~cm}^{-1}$, by the sum of 60 scans. Fourier Transform Attenuated Total Reflection (FTIR-ATR) infrared spectra were obtained using a Cary model 660 spectrometer. The spectra were recorded at room temperature in the region of 580 to $4000 \mathrm{~cm}^{-1}$ with a resolution of $4 \mathrm{~cm}^{-1}$ with 32 scans.

\subsection{UV-Vis Spectroscopy}

The UV-Vis absorption spectra of chalcones were obtained using a GENESYS ${ }^{\mathrm{TM}} 10 \mathrm{~S}$ spectrophotometer (Thermo Scientific, Waltham, MA, USA) in the wavelength range of 190 to $800 \mathrm{~nm}$. The samples were prepared at a concentration of $0.1 \mathrm{mmol} \mathrm{L}^{-1}$ using ethanol as a solvent to perform the absorption measurements in the UV-Vis region. All absorption measurements were carried out at room temperature in quartz cells of a $1 \mathrm{~cm}$ optical path.

\subsection{Cyclic Voltammetry Experiments}

Cyclic voltammetry experiments were performed using a conventional glass electrochemical cell containing three electrodes and connected to a potentiostat/galvanostat, model PGSTAT 101 (Metrohm, Herisau, AR., Switzerland), which was controlled by computer using the software NOVA 2.1. A disk glassy carbon $\left(0.071 \mathrm{~cm}^{2}\right)$ was the working electrode, while two platinum plates, one with $1.0 \mathrm{~cm}^{2}$ and the other with $0.5 \mathrm{~cm}^{2}$, were the auxiliary and reference electrodes, respectively. Prior to the electrochemical measurements, the working electrode was manually polished with a $3 \mu \mathrm{m}$ diamond paste, followed by washing with ultrapure water. Next, the electrode was washed in ethyl alcohol and in water under ultrasound irradiation. The cyclic voltammograms of both chalcones were obtained in dichloromethane at $50 \mathrm{mV} \mathrm{s}^{-1}$ and at room temperature $\left(\cong 25^{\circ} \mathrm{C}\right)$. The working solutions contained $50 \mathrm{mmol} \mathrm{L}{ }^{-1}$ of tetrabutylammonium perchlorate and $0.5 \mathrm{mmol} \mathrm{L}^{-1}$ of one of the investigated chalcones. All solutions were previously deaerated by nitrogen bubbling $\mathrm{N}_{2}(\mathrm{~g})$ for $5 \mathrm{~min}$.

\subsection{Computational Methods}

The computational calculations of quantum chemistry, based on the Functional Density Theory (DFT), were performed using the Gaussian 09 software package [? ]. The B3LYP functional was used along with the 6-31 G $(\mathrm{d}, \mathrm{p})$ basis set. The molecular structure of the 3-Nitro and 4-Nitro chalcones were 
designed in the ChemSketch program [? ], according to the data obtained from the ${ }^{1} \mathrm{H}$ and ${ }^{13} \mathrm{C}$ NMR spectroscopy. The structure was optimized, and the wavenumbers and atomic displacements were calculated for each vibrational mode. The calculations of each of the optimized molecular structures do not provide any imaginary frequency. The wave functions of the electronic densities were also obtained for the optimized structures of the molecules under study. In addition, DFT calculations were performed to obtain the Kohn-Sham orbitals and the Highest Occupied Molecular Orbital (HOMO) and the Lowest Unoccupied Molecular Orbital (LUMO), as well as the following quantum chemical parameters: vertical ionization energy, electron affinity, chemical potential, electronegativity, global hardness, and electrophilicity index. The Chemcraft program was used to build the shape of the orbitals HOMO and LUMO [? ]. The theoretical frequencies observed in the Raman spectrum were scaled through adjustments of least squares, as suggested by Rauhut and Pulay [? ]. For the chalcones, dual-scaling factors with values of 0.9626 for frequencies below $2000 \mathrm{~cm}^{-1}$ and 0.9440 for frequencies above $2000 \mathrm{~cm}^{-1}$ were used. The calculated vibrational wavenumbers were adjusted for comparison with the experimental frequencies of the Raman and infrared spectra. The descriptions of the normal modes of vibration were made based on the potential energy distribution (PED) using the VEDA program [?].

\subsection{Microbiological Characterization}

\subsubsection{Bacterial Material}

Microorganisms used in the tests were obtained through the Laboratory of Microbiology and Molecular Biology (LMBM) of the Regional University of Cariri (URCA). Standard and resistant bacterial strains were used: Escherichia coli 06 and Staphylococcus aureus 10. The strain which overexpresses the NorA efflux pump is S. aureus 1199-B. All strains were kept in Agar heart infusion (HIA, Difco Laboratories Ltd., Jersey, NJ, USA). Before the assays, the strains were cultivated for $18 \mathrm{~h}$ at $37^{\circ} \mathrm{C}$ in brain and heart infusion broth (BHI, Difco Laboratories Ltd., Jersey, NJ, USA) the Ethidium bromide was obtained by (Sigma Aldrich).

\subsubsection{Drugs and Substances}

The antibiotics Norfloxacin (Nor), Gentamicin (Gen), Ciprofloxacin (Cip) and the Ethidium dye Bromide (EtBr), as well as chlorpromazine (CPZ) were obtained from Sigma Chemical Corp., (St. Louis, MO, USA).

\subsubsection{Intrinsic Antibacterial Activity}

The test Eppendorf tubes were prepared in triplicate for each bacterium (in an equivalent concentration using the McFarland scale 0.5) and each substance, each one containing $900 \mu \mathrm{L}$ of $10 \%$ $\mathrm{BHI}+150 \mu \mathrm{L}$ of the inoculum (corresponding to $10 \%$ of the total solution) for the MIC. A total of $100 \mu \mathrm{L}$ of the final inoculum solution was added to each well of the microdilution plate, and then the serial microdilution was performed with the $100 \mu \mathrm{L}$ solution of chalcones per column, varying at concentrations of $512 \mu \mathrm{g} / \mathrm{mL}$ in the first well to $8 \mu \mathrm{g} / \mathrm{mL}$ in the last well. Microdilutions were performed in triplicate. The plates were taken to the incubator for $24 \mathrm{~h}$ at $37^{\circ} \mathrm{C}$. The MIC was determined by adding $20 \mu \mathrm{L}$ of resazurin in each well and observing the color change after $1 \mathrm{~h}$. All experiments were performed in triplicate [? ].

\subsubsection{Modulation of Antibiotic}

Eppendorf tubes were prepared, each one containing substances corresponding to the volume of the sub-inhibitory concentration (MIC/8), a variable amount of $10 \% \mathrm{BHI}$ according to the volume of the sub-inhibitory concentration and $150 \mu \mathrm{L}$ of the bacterial suspension (corresponding to $10 \%$ of the solution). For the controls, the Eppendorf tubes were prepared with $1.5 \mathrm{~mL}$ of a solution containing $1350 \mu \mathrm{L}$ of $\mathrm{BHI}(10 \%)$ and $150 \mu \mathrm{L}$ of microorganism suspension. The plate was filled numerically by 
adding $100 \mu \mathrm{L}$ of this solution into each well. Then, serial micro dilutions were performed with $100 \mu \mathrm{L}$ of the antibiotic agent. The reading was carried out by adding $20 \mu \mathrm{L}$ of resazurin $(0.05 \mathrm{~g} / \mathrm{mL})$ to each well and through the observation of the change in color after $1 \mathrm{~h}$. All experiments were performed in triplicate [?].

\subsection{Ethidium Bromide MIC}

The antibiotics and the chalcones under study were first dissolved in dimethyl sulfoxide (DMSO). Subsequently, the compounds dissolved in DMSO underwent a new dilution, this time in sterile water. The chlorpromazine and ethidium bromide were dissolved in sterile water and CCCP in methanol/water $(1: 1, v / v)$. All the compounds were stored at $-20{ }^{\circ} \mathrm{C}$ at a final concentration of $1024 \mu \mathrm{g} / \mathrm{mL}$. To evaluate the inhibition capacity of the efflux pumps, the MICs of the strain-specific antibiotics as well as ethidium bromide used as controls were compared with the MICs of their associations with the standard inhibitors. The test solutions used in the aforementioned controls were prepared in Eppendorf's microtubes containing medium and inoculum. The test solutions used for comparison were added to the chalcones and standard inhibitors in amounts that correspond to MIC/8 (sub-inhibitory concentration). Then, $100 \mu \mathrm{L}$ of Eppendorf's content were transferred to a 96-well plate microtiter tray with two-fold serial dilution by adding $100 \mu \mathrm{L}$ of antibiotics and ethidium bromide, with a final concentration ranging from 0.5 to $512 \mu \mathrm{g} / \mathrm{mL}$. The trays were incubated at $37^{\circ} \mathrm{C}$ for $24 \mathrm{~h}$, and bacterial growth was revealed by staining with resazurin [? ].

\subsection{Statistical Analysis of Microbiological Results}

The results were analyzed using the statistical program GraphPad Prisma 5.0. All antibacterial assays were performed in triplicate, and the results were analyzed using a two-way ANOVA test, using the geometric mean of the triplicates as the central data and standard deviation of the mean. A post-hoc Bonferroni test was then performed (where $p<0.05$ and $p<0.0001$ are considered significant and $p>0.05$ not significant). Possible discrepancies were checked with multiple $T$-tests.

\section{Conclusions}

Two chalcones, (E)-1-(2-hydroxy-3,4,6-trimethoxyphenyl)-3-(3-nitrophenyl)prop-2-en-1-one (1) and (E)-1-(2-hydroxy-3,4,6-trimethoxyphenyl)-3-(4-nitrophenyl)prop-2-en-1-one (2), were synthesized by the Claisen-Schmidt condensation reaction in a basic medium between the natural compound 2-hydroxy-3,4,6-trimethoxyacetophenone and isomeric nitrobenzaldehydes. In addition, the vibrational spectra of polycrystalline samples by FT-IR spectroscopy (between 670 and $3600 \mathrm{~cm}^{-1}$ ), FT-Raman (between 0 and $3600 \mathrm{~cm}^{-1}$ ) were reported for the first time. The DFT calculations were performed using the Gaussian 09 package with the B3LYP functional set and the 6-31G base set (d, p), in order to obtain information on the normal modes of vibration, allowing a complete assignment and various quantum chemical parameters of the synthesized substances. Both chalcones did not show good responses when associated with the antibiotics Ciprofloxacin, and Cephalexin against S. aureus and E. coli strains tested. However, a significant potentiating of the Gentamicin activity against $S$. aureus and E. coli strains was observed for chalcone 2 . Therefore, these results demonstrate that the chalcone 2 compound presents potential as an adjuvant of the Gentamicin, probably due to its higher reactivity and lipophilicity.

Supplementary Materials: The following are available online at http://www.mdpi.com/2076-3417/10/14/4713/s1, Figures S1 and S3: ${ }^{1} \mathrm{H}$ NMR spectra, Figures S2 and S4: ${ }^{13} \mathrm{C}$ NMR spectra, Tables S5 and S6: vibrational wavenumbers of chalcones 1 and 2.

Author Contributions: Investigation, and writing — original draft preparation, P.T.d.S.; conceptualization, funding acquisition and supervision, H.S.d.S.; methodology, E.M.M.; software, T.S.d.F.; validation, A.L.A.B.L. and H.M.B.; performed DFT calculations, E.S.M.; co-supervised, and reviewed the manuscript, P.N.B.; data curation, P.d.L.-N.; performed the infrared measurements, D.M.S.J., M.S.d.S.J.; funding acquisition, writing-review and editing, and aided in the spectroscopic analyses. A.M.R.T. and N.M.; visualization, A.A.C.A.; formal analysis and reviewed the manuscript, C.E.S.N.; project administration and methodology N.M. and H.D.M.C. All authors have read and agreed to the published version of the manuscript. 
Funding: This research was funded by Conselho Nacional de Desenvolvimento Científico e Tecnológico-CNPq, Grant number $n^{\circ}: 305719 / 2018-1$.

Acknowledgments: We thank FUNCAP, CAPES, and CNPq for their financial support. The authors also thank Antonio César Honorato Barreto for his support in FT-Raman measurements. We would like to thank the Northeastern Center for the Use and Application of Nuclear Magnetic Resonance (CENAUREM) for the spectra performed. Computational support from CENAPAD-UFC for the use of the Gaussian09 software package available through the project "proj373" is also acknowledged.

Conflicts of Interest: The authors declare no conflict of interest.

\section{References}

1. Ninomiya, M.; Koketsu, M. Minor Flavonoids (Chalcones, Flavanones, Dihydrochalcones, and Aurones). In Natural Products, 1st ed.; Ramawat, K.G., Mérillon, J.M., Eds.; Springer: Berlin/Heidelberg, Germany, 2013; Volume 1, pp. 1867-1900.

2. Ávila, H.P.; Smania, E.D.F.A.; Monache, F.D.; Smânia, A. Structure-activity relationship of antibacterial chalcones. Bioorg. Med. Chem. 2008, 16, 9790-9794. [CrossRef] [PubMed]

3. Hazarkhani, H.; Kumar, P.; Kondiram, K.S.; Gadwal, I.M.S. Highly Selective Claisen-Schmidt Condensation Catalyzed by Silica Chloride Under Solvent-Free Reaction Conditions. Synth. Commun. 2010, 40, 2887-2896. [CrossRef]

4. Orlíková, B.; Tasdemir, D.; Golais, F.; Dicato, M.; Diederich, M. Dietary chalcones with chemopreventive and chemotherapeutic potential. Genes Nutr. 2011, 6, 125-147. [CrossRef]

5. Rozmer, Z.; Perjési, P. Naturally occurring chalcones and their biological activities. Phytochem. Rev. 2014, 15, 87-120. [CrossRef]

6. Gaonkar, S.; Vignesh, U.N. Synthesis and pharmacological properties of chalcones: A review. Res. Chem. Intermed. 2017, 43, 6043-6077. [CrossRef]

7. Verma, S.; Srivastava, A.K.; Pandey, O.P. A Review on Chalcones Synthesis and their Biological Activity. PharmaTutor 2018, 6, 22-39. [CrossRef]

8. Rani, A.; Anand, A.; Kumar, K.; Kumar, V. Recent developments in biological aspects of chalcones: The odyssey continues. Expert Opin. Drug Discov. 2019, 14, 249-288. [CrossRef] [PubMed]

9. Bandeira, P.N.; Lemos, T.L.G.; Santos, H.S.; De Carvalho, M.C.S.; Pinheiro, D.P.; Filho, M.O.D.M.; Pessoa, C.; Barros-Nepomuceno, F.W.A.; Rodrigues, T.H.S.; Ribeiro, P.R.V.; et al. Synthesis, structural characterization, and cytotoxic evaluation of chalcone derivatives. Med. Chem. Res. 2019, 28, 2037-2049. [CrossRef]

10. Zhang, B.; Duan, D.; Ge, C.; Yao, J.; Liu, Y.; Li, X.; Fang, J. Synthesis of Xanthohumol Analogues and Discovery of Potent Thioredoxin Reductase Inhibitor as Potential Anticancer Agent. J. Med. Chem. 2015, 58, 1795-1805. [CrossRef]

11. Rampa, A.; Bartolini, M.; Pruccoli, L.; Naldi, M.; Iriepa, I.; Moraleda, I.; Belluti, F.; Gobbi, S.; Tarozzi, A.; Bisi, A. Exploiting the Chalcone Scaffold to Develop Multifunctional Agents for Alzheimer's Disease. Molecules 2018, 23, 1902. [CrossRef]

12. Hameed, A.; Masood, S.; Hameed, A.; Ahmed, E.; Sharif, A.; Abdullah, M.I. Anti-malarial, cytotoxicity and molecular docking studies of quinolinyl chalcones as potential anti-malarial agent. J. Comput. Mol. Des. 2019, 33, 677-688. [CrossRef] [PubMed]

13. Cole, A.L.; Hossain, S.; Cole, A.M.; Phanstiel, O.; Iv, O.P. Synthesis and bioevaluation of substituted chalcones, coumaranones and other flavonoids as anti-HIV agents. Bioorg. Med. Chem. 2016, 24, 2768-2776. [CrossRef] [PubMed]

14. Sivakumar, P.M.; Prabhakar, P.K.; Doble, M. Synthesis, antioxidant evaluation, and quantitative structure-activity relationship studies of chalcones. Med. Chem. Res. 2010, 20, 482-492. [CrossRef]

15. Božić, D.D.; Milenković, M.; Ivković, B.; Ćirković, I. Antibacterial activity of three newly-synthesized chalcones \& synergism with antibiotics against clinical isolates of methicillin-resistant Staphylococcus aureus. Indian J. Med. Res. 2014, 140, 130-137.

16. Tran, T.-D.; Do, T.-H.; Tran, N.C.; Ngo, T.-D.; Huynh, T.-N.-P.; Tran, C.-D.; Thai, K.-M. Synthesis and anti Methicillin resistant Staphylococcus aureus activity of substituted chalcones alone and in combination with non-beta-lactam antibiotics. Bioorg. Med. Chem. Lett. 2012, 22, 4555-4560. [CrossRef] 
17. De Mello, T.F.; Cardoso, B.M.; Bitencourt, H.R.; Donatti, L.; Aristides, S.M.; Lonardoni, M.V.C.; Silveira, T.G. Ultrastructural and morphological changes in Leishmania (Viannia) braziliensis treated with synthetic chalcones. Exp. Parasitol. 2016, 160, 23-30. [CrossRef]

18. Teixeira, A.M.; Dos Santos, H.S.; Bandeira, P.; Julião, M.; Freire, P.; Lima, V.; Cruz, B.; Da Silva, P.; Coutinho, H.D.M.; Sena, D. Structural, spectroscopic and microbiological characterization of the chalcone 2E-1-(2'-hydroxy-3' , 4' , 6' -trimethoxyphenyl)-3-(phenyl)-prop-2-en-1-one derived from the natural product 2-hydroxy-3,4,6-trimethoxyacetophenone. J. Mol. Struct. 2019, 1179, 739-748. [CrossRef]

19. Santiago, R.; Freire, P.; Ayala, A.P.; Teixeira, A.M.; Dos Santos, H.S.; Bandeira, P.; Gonçalves, F.; Oliveira, M.; Cruz, B.; Sena, D. Crystal structure, vibrational spectra and quantum chemical parameters of 2-hydroxy-3,4,6-trimethoxyacetophenone isolated from the Croton anisodontus Müll. Arg. (Euphorbiaceae). J. Mol. Struct. 2018, 1171, 815-826. [CrossRef]

20. Besharati-Seidani, T.; Keivanloo, A.; Kaboudin, B.; Yoshida, A.; Yokomatsu, T. Regioselective synthesis of 2,3-disubstituted 1-alkyl pyrrolo[2,3-b] quinoxalines through palladium-catalyzed Heck reaction of chalcones and evaluation of their anti-bacterial activities. Tetrahedron 2018, 74, 2350-2358. [CrossRef]

21. Al-Amood, H.; Al-Hadithi, H.T.; Dadhil, F.G. Structure-Antimicrobial Activity Relationship Investigation of Some Butadiene and Chalcone Derivatives. J. Life Sci. 2013, 7, 705-711.

22. Sivakumar, P.M.; Priya, S.; Doble, M. Synthesis, Biological Evaluation, Mechanism of Action and Quantitative Structure-Activity Relationship Studies of Chalcones as Antibacterial Agents. Chem. Biol. Drug Des. 2009, 73, 403-415. [CrossRef] [PubMed]

23. Mora, C.L.; Castaño, J.; Jaramillo, M.C. Actividad inhibitoria de dihidroxifenilpropenona sobre $\beta$-lactamasa de Enterobacter cloacae: Estudio preliminar en el desarrollo de fármacos para enfrentar la resistencia bacteriana. Biomédica 2013, 34, 114. [CrossRef]

24. Chu, W.-C.; Bai, P.-Y.; Yang, Z.-Q.; Cui, D.-Y.; Hua, Y.-G.; Yang, Y.; Yang, Q.; Zhang, E.; Qin, S. Synthesis and antibacterial evaluation of novel cationic chalcone derivatives possessing broad spectrum antibacterial activity. Eur. J. Med. Chem. 2018, 143, 905-921. [CrossRef]

25. Brown, E.D.; Wright, G.D. Antibacterial drug discovery in the resistance era. Nature 2016, 529, $336-343$. [CrossRef] [PubMed]

26. Laxminarayan, R. Antibiotic effectiveness: Balancing conservation against innovation. Science 2014, 345, 1299-1301. [CrossRef] [PubMed]

27. Wachino, J.-I.; Jin, W.; Kimura, K.; Kurosaki, H.; Sato, A.; Arakawa, Y. Sulfamoyl Heteroarylcarboxylic Acids as Promising Metallo- $\beta$-Lactamase Inhibitors for Controlling Bacterial Carbapenem Resistance. mBio 2020, 11, 03144-19. [CrossRef] [PubMed]

28. Fukui, K. The Role of Frontier Orbitals in Chemical Reactions (Nobel Lecture). Angew. Chem. Int. Ed. 1982, 21, 801-809. [CrossRef]

29. Parr, R.G. Density Functional Theory of Atoms and Molecules; Springer Science and Business Media LLC.: Berlin/Heidelberg, Germany, 1980; pp. 5-15.

30. Parr, R.G.; Szentpály, L.V.; Liu, S. Electrophilicity Index. J. Am. Chem. Soc. 1999, 121, 1922-1924. [CrossRef]

31. Parr, R.G.; Pearson, R.G. Absolute hardness: Companion parameter to absolute electronegativity. J. Am. Chem. Soc. 1983, 105, 7512-7516. [CrossRef]

32. Paulai, F.R.; Serrano, S.H.P.; Tavares, L.C. Aspectos mecanísticos da bioatividade e toxicidade de nitrocompostos. Química Nova 2009, 32, 1013-1020. [CrossRef]

33. Nepali, K.; Lee, H.-Y.; Liou, J.-P. Nitro-Group-Containing Drugs. J. Med. Chem. 2018, 62, $2851-2893$. [CrossRef] [PubMed]

34. Spackman, M.A.; McKinnon, J. Fingerprinting intermolecular interactions in molecular crystals. CrystEngComm 2002, 4, 378-392. [CrossRef]

35. Prabhu, S.R.; Jayarama, A.; Chandrasekharan, K.; Upadhyaya, V.; Ng, S.W. Synthesis, growth, structural characterization, Hirshfeld analysis and nonlinear optical studies of a methyl substituted chalcone. J. Mol. Struct. 2017, 1136, 244-252. [CrossRef]

36. Mayo, D.W.; Miller, F.A.; Hannah, R.W. Course Notes on the Interpretation of Infrared and Raman Spectra; John Wiley \& Sons, Inc.: Hoboken, NJ, USA, 2003.

37. Frisch, M.J.; Trucks, G.W.; Schlegel, H.B.; Scuseria, G.E.; Robb, M.A.; Cheeseman, J.R.; Scalmani, G.; Barone, V.; Mennucci, B.; Petersson, G.A.H.; et al. Gaussian 09; Gaussian, Inc.: Wallingford, CT, USA, 2009. 
38. ACD/Structure Viewer-Freeware; version 2016.1.1; Advanced Chemistry Development, Inc.: Toronto, ON, Canada, 2016.

39. Andrienko, G.A. Chemcraft. Available online: www.chemcraftprog.com (accessed on 24 June 2020).

40. Rauhut, G.; Pulay, P. Transferable Scaling Factors for Density Functional Derived Vibrational Force Fields. J. Phys. Chem. 1995, 99, 3093-3100. [CrossRef]

41. Jamróz, M.; Dobrowolski, J. Potential energy distribution (PED) analysis of DFT calculated IR spectra of the most stable Li, Na, and Cu(I) diformate molecules. J. Mol. Struct. 2001, 565, 475-480. [CrossRef]

42. Leal, A.L.A.B.; Bezerra, C.F.; Rocha, J.E.; Dos Santos, A.T.L.; Da Cruz, R.P.; Carneiro, J.N.P.; Sales, D.L.; De Freitas, T.S.; Tintino, S.R.; Almeida, W.D.O.; et al. Piper cernuum Vell.: Chemical profile and antimicrobial potential evaluation. Ind. Crop. Prod. 2019, 140, 111577. [CrossRef]

43. Salazar, G.J.T.; De Sousa, J.P.; Lima, C.N.F.; Lemos, I.C.S.; Da Silva, A.R.P.; De Freitas, T.S.; Coutinho, H.D.M.; Da Silva, L.E.; Amaral, W.D.; Deschamps, C. Phytochemical characterization of the Baccharis dracunculifolia DC (Asteraceae) essential oil and antibacterial activity evaluation. Ind. Crop. Prod. 2018, 122, 591-595. [CrossRef]

44. Tintino, S.R.; Oliveira-Tintino, C.D.; Campina, F.F.; Silva, R.L.; Costa, M.D.S.; Menezes, I.R.; Calixto-Júnior, J.T.; Siqueira-Júnior, J.P.; Coutinho, H.D.M.; Leal-Balbino, T.C.; et al. Evaluation of the tannic acid inhibitory effect against the NorA efflux pump of Staphylococcus aureus. Microb. Pathog. 2016, 97, 9-13. [CrossRef]

(C) 2020 by the authors. Licensee MDPI, Basel, Switzerland. This article is an open access article distributed under the terms and conditions of the Creative Commons Attribution (CC BY) license (http://creativecommons.org/licenses/by/4.0/). 